\title{
Correction to: Weighted scoring elections: is Borda best?
}

D. Marc Kilgour ${ }^{1}\left[\right.$ - Jean-Charles Grégoire ${ }^{2}$ - Angèle M. Foley ${ }^{1}$

Published online: 26 November 2021

(c) The Author(s), under exclusive licence to Springer-Verlag GmbH Germany, part of Springer Nature 2021

\section{Correction to: Social Choice and Welfare https://doi.org/10.1007/s00355-021-01347-6}

In the original publication of the article, some of the data in Tables 5 and 7 were wrong. The correct Tables 5 and 7 should read as given below.

The original has been corrected.

The original article can be found online at https://doi.org/10.1007/s00355-021-01347-6.

$\triangle$ D. Marc Kilgour

mkilgour@wlu.ca

Jean-Charles Grégoire

gregoire@emt.inrs.ca

Angèle M. Foley

ahamel@wlu.ca

1 Department of Mathematics, Wilfrid Laurier University, Waterloo, ON N2L 3C5, Canada

2 Institut National de la Recherche Scientifique, Montréal, QC H5A 1K6, Canada 
Table 5 Condorcet efficiency of Borda variants

\begin{tabular}{llllllllllll}
\hline Case & $I 3$ & $I 2$ & $L 3$ & $I$ & $L 2$ & $C v$ & $I / 2$ & $L$ & $I / 3$ & $L / 2$ & $L / 3$ \\
\hline 3-IAC & 88.57 & 89.49 & 90.25 & 92.27 & 92.27 & 92.53 & 91.48 & 91.48 & 85.90 & 81.83 & 76.47 \\
3-IC & 78.51 & 79.06 & 80.90 & 85.81 & 85.81 & 88.76 & 91.12 & 91.12 & 87.69 & 85.57 & 82.46 \\
3-Spa & 62.50 & 66.03 & 71.20 & 80.86 & 80.86 & 87.86 & 83.44 & 83.44 & 66.84 & 59.66 & 53.66 \\
4-IAC & 75.43 & 77.64 & 83.06 & 84.27 & 86.55 & 88.21 & 88.02 & 87.80 & 84.00 & 78.20 & 71.73 \\
4-IC & 67.32 & 70.10 & 76.81 & 78.78 & 82.10 & 85.59 & 86.31 & 87.01 & 84.38 & 80.84 & 76.33 \\
4-Spa & 46.33 & 50.53 & 62.97 & 68.66 & 76.75 & 87.37 & 88.04 & 87.19 & 80.03 & 74.99 & 73.68 \\
5-IAC & 63.08 & 66.30 & 77.13 & 76.23 & 82.54 & 85.04 & 84.27 & 85.41 & 83.05 & 77.88 & 70.76 \\
5-IC & 60.12 & 63.79 & 74.97 & 74.48 & 80.93 & 84.49 & 84.03 & 86.31 & 83.68 & 79.63 & 73.63 \\
5-Spa & 35.47 & 39.63 & 56.75 & 58.16 & 72.57 & 82.36 & 82.35 & 76.84 & 80.09 & 58.35 & 54.32 \\
6-IAC & 53.70 & 57.81 & 72.40 & 69.76 & 78.65 & 82.74 & 81.33 & 84.10 & 81.52 & 76.28 & 68.61 \\
6-IC & 53.84 & 57.70 & 73.26 & 69.77 & 79.56 & 83.01 & 81.43 & 84.52 & 81.53 & 77.29 & 70.27 \\
6-Spa & 29.22 & 32.62 & 52.03 & 49.70 & 70.73 & 82.89 & 75.99 & 80.09 & 80.63 & 66.17 & 63.73 \\
\hline
\end{tabular}

Table 7 Standard Borda versus Cervone

\begin{tabular}{|c|c|c|c|c|c|c|c|c|c|}
\hline \multirow[b]{2}{*}{ Case } & \multirow[b]{2}{*}{$F$} & \multicolumn{4}{|c|}{ Standard Borda $(L)$} & \multicolumn{4}{|c|}{ Cervone $(C v)$} \\
\hline & & $G$ & $C E$ & $E[D]$ & PMax & $G$ & $C E$ & $E[D]$ & PMax \\
\hline 3-IAC & 94.05 & 86.04 & 91.48 & 0.1603 & 91.98 & 87.00 & 92.53 & 0.142 & 92.98 \\
\hline 3-IC & 91.80 & 83.65 & 91.12 & 0.1631 & 91.85 & 81.06 & 88.76 & 0.206 & 89.74 \\
\hline 3-Spa & 100 & 83.44 & 83.44 & 0.3312 & 83.44 & 87.86 & 87.86 & 0.251 & 87.86 \\
\hline 4-IAC & 83.77 & 73.55 & 87.80 & 0.2261 & 89.17 & 73.86 & 88.21 & 0.222 & 89.50 \\
\hline 4-IC & 82.69 & 71.95 & 87.01 & 0.2402 & 88.48 & 70.72 & 85.59 & 0.276 & 87.11 \\
\hline 4-Spa & 100 & 87.19 & 87.19 & 0.2562 & 87.19 & 87.37 & 87.37 & 0.294 & 87.37 \\
\hline 5-IAC & 76.68 & 65.49 & 85.41 & 0.2952 & 86.49 & 65.10 & 85.04 & 0.312 & 85.91 \\
\hline 5 -IC & 75.22 & 64.92 & 86.31 & 0.2809 & 87.15 & 63.29 & 84.49 & 0.326 & 85.49 \\
\hline 5-Spa & 100 & 76.84 & 76.84 & 0.5189 & 76.84 & 82.36 & 82.36 & 0.435 & 82.36 \\
\hline 6-IAC & 67.69 & 56.93 & 84.10 & 0.3522 & 84.63 & 55.99 & 82.74 & 0.391 & 83.33 \\
\hline 6-IC & 68.43 & 57.84 & 84.53 & 0.3413 & 85.18 & 56.81 & 83.01 & 0.389 & 83.60 \\
\hline 6-Spa & 100 & 80.09 & 80.10 & 0.4543 & 80.10 & 82.89 & 82.89 & 0.437 & 82.89 \\
\hline
\end{tabular}

$F$ Probability $C^{*}$ exists, $G$ (Unconditional) Probability Winner is $C^{*}$. All probabilities in $\%$

Publisher's Note Springer Nature remains neutral with regard to jurisdictional claims in published maps and institutional affiliations. 